\title{
A study of feto-maternal outcome in bleeding per vaginum in first trimester of pregnancy
}

\author{
Jaydeep J. Bhatu*, Darshil S. Prajapati
}

Department of Obstetrics and Gynecology, GMERS Medical College and Hospital, Sola, Ahmedabad, Gujarat, India

Received: 03 January 2020

Accepted: 01 February 2020

\section{*Correspondence:}

Dr. Jaydeep J. Bhatu,

E-mail: bhatujaydeep@gmail.com

Copyright: (C) the author(s), publisher and licensee Medip Academy. This is an open-access article distributed under the terms of the Creative Commons Attribution Non-Commercial License, which permits unrestricted non-commercial use, distribution, and reproduction in any medium, provided the original work is properly cited.

\begin{abstract}
Background: Bleeding per vaginum in the first trimester is a common obstetric entity. Four major causes of pathological bleeding in $1^{\text {st }}$ trimester are miscarriage, ectopic pregnancy, implantation bleeding of pregnancy and cervical pathology. The purpose of this study was to investigate and understand the effect of first trimester vaginal bleeding on maternal and perinatal outcomes in the local population to which our hospital serves. Objective of this study was to estimate the degree of association between first-trimester bleeding and miscarriage, pregnancy outcomes in women with threatened abortion, various maternal complications and outcome of labor in pregnancy complicated by first-trimester bleeding and adverse fetal outcomes affected with first trimester bleeding.

Methods: This prospective observational study was carried out on 110 women attending hospital with history of first trimester vaginal bleeding at a tertiary health center - sola civil hospital Ahmedabad for a period of twelve months.

Results: Majority (69\%) of first trimester bleeding occurs in age group of 21-30 years and majority of patients were primigravida constituting $53 \%$ out of 110 patients, 48 patients presented with abortions, out of which 26 had threatened abortion and 22 had other abortions. Primi para with previous history of bleeding per vaginum had more chances to go in full term in present pregnancy.

Conclusions: Patients presenting with heavy bleeding per vaginum ended up in pregnancy loss and thus a poor outcome. In the presence of sub-chorionic hematoma, the prognosis of pregnancy is greatly affected as the risk of preterm, IUGR and especially miscarriages increase significantly.
\end{abstract}

Keywords: Abortion, Bleeding per vaginum, H. Mole, Medical termination of pregnancy, Placenta previa, Subchorionic hematoma

\section{INTRODUCTION}

Pregnancy is one of the most significant events in a woman's life. First trimester is a dynamic period which spans fertilization, implantation and organogenesis. Bleeding per vaginum in the first trimester is a common obstetric entity complicating $20-25 \%$ of all pregnancies. ${ }^{1,2}$ It can cause worry and anxiety for the mother, family as well as the care providers. The significance of bleeding in early pregnancy in a given patient may range from an in consequential episode to a life- threatening emergency.
Four major causes of pathological bleeding in $1^{\text {st }}$ trimester are miscarriage (threatened, inevitable, incomplete or complete), ectopic pregnancy, implantation bleeding of pregnancy and cervical pathology. ${ }^{3}$ Half of the women who experience first trimester vaginal bleeding will continue their pregnancies, and the other half will experience an abortion. If pregnancy continues poor maternal and foetal outcome such as preterm delivery, preterm premature rupture of membranes (PPROM), placental abruption, preeclampsia and intra uterine growth restriction (IUGR) may occur suggestive of underlying placental dysfunction. It is also known that 
maternal age, systemic diseases such as diabetes mellitus, hypothyroidism, infertility treatment, thrombophilia, maternal weight and uterine structural anomalies increase the risk of abortus imminens. ${ }^{4}$

\section{Objectives of this study were}

- To investigate and understand the effect of first trimester vaginal bleeding on maternal and perinatal outcomes in the local population to which our hospital serves.

- To estimate the degree of association between firsttrimester bleeding and miscarriage.

- To assess pregnancy outcomes in women with threatened abortion in the first trimester.

- To study various maternal complications and outcome of labour in pregnancy complicated by firsttrimester bleeding.

- To study the adverse foetal outcomes affected with first trimester bleeding including preterm delivery, low birth weight and small for gestational age.

\section{METHODS}

This prospective observational study was carried out on 110 women attending our hospital with history of first trimester vaginal bleeding at a tertiary health centre - sola civil hospital Ahmedabad from June 2018 to May 2019 for a period of twelve months. Patients with history of amenorrhea and positive urine pregnancy test with bleeding per vaginum in first trimester were included.

\section{Design}

In this study took complete history followed by complete examination (general, physical and gynaecological) of all the patients at booking visit. The patients were followed up regularly in antenatal clinic and repeat ultrasound scans were done as required. The design of this study is used to study a relationship between variables. The independent variable here is a history of vaginal bleeding $\&$ the dependent variable is the pregnancy outcome. A structured proforma was used to collect information and followed till their pregnancy terminated.

\section{Inclusion criteria}

- Months of amenorrhoea of less than 3 months

- Positive pregnancy test

- Bleeding per vaginum

- Previous regular cycles

- Absence of cervical and vaginal pathology,

\section{Exclusion criteria}

- $\quad$ Patient comes with vaginal bleeding following MTP

- All patients with more than 12 completed weeks of gestation

- Bleeding tendencies
- History of mechanical trauma during the present pregnancy

- Patients refusing participation

- Patients with chromosomal abnormalities.

\section{Statistical analysis}

- Quantitative variables were compared using Independent t-test/Mann- Whitney test

- Qualitative variables were compared using ChiSquare test/Fisher's Exact test. A p value of $<0.05$ was considered statistically significant.

The vaginal bleeding histories included the duration of bleeding in days, the severity of bleeding and associated abdominal pain.

Females with previous short menstrual cycles experience more episodes of bleeding or spotting in their first trimester.

Bleeding was thereafter categorized as spotting, moderate, or heavy bleeding according to the selfassessed degree of vaginal bleeding.

Spotting is bleeding reported by the patient as scant or traces of blood and visualized by the provider as staining of glove or dirty discharge.

Moderate bleeding is reported by the patient as "like menses." It is visualized by the provider as a small amount of blood in the vagina and at the cervix.

Heavy bleeding is reported by the patient as "more than a menses." It is visualized by the provider as a moderate to severe amount of blood in the vagina and at the cervix.

BT, CT, PTINR and APTT was done of all the patients to rule out bleeding tendencies.

Ultrasound examination was done in all subjects who were included in this investigation. All such patients were prospectively followed throughout the pregnancy and intrapartum period and their outcomes were studied. Postpartum follow-up was performed by telephonic talk or medical record review for 3 months.

\section{The fetal outcome of the pregnancy was categorized as}

Non-viable outcome (termination of pregnancy before 20 weeks)

- Spontaneous or induced termination

- Congenital malformations which was terminated before 20 weeks viable outcome (continuation of pregnancy after 20 weeks)

- Preterm delivery

- $\quad$ Low birth weight $(<2500 \mathrm{~kg})$

- Intra uterine growth retardation 
- Perinatal death

- $\quad$ NICU admission and

- Full term live birth with healthy fetus.

The maternal outcome (only from those patients in which pregnancy continued beyond 20 weeks) as

- Anemia (pallor and $\mathrm{Hb}<10 \mathrm{gm} \%$ at the time of bleeding)

- Preeclampsia syndromes

- PPROM (membrane rupture < 37 weeks of gestation)

- Placental abruption

- Placenta previa

- Post-partum hemorrhage,

- Caesarean delivery and

- D and E.

\section{RESULTS}

This is a prospective study of first 110 cases of first trimester bleeding from our unit from June 2018 to May 2019 , analyzed with regards to feto-maternal outcome.

\section{Observations from this study are as follows}

Table 1: Age distribution.

\begin{tabular}{|lll|}
\hline Age (in years) & Number & Percentage \\
\hline$<20$ & 22 & $20 \%$ \\
\hline $21-30$ & 76 & $69 \%$ \\
\hline$\geq 31$ & 12 & $11 \%$ \\
\hline Total & $\mathbf{1 1 0}$ & $\mathbf{1 0 0}$ \\
\hline
\end{tabular}

Table 1 shows that in this study the age group ranged from 18-35 and majority (69\%) of first trimester bleeding occurs in age group of 21-30 years.

Table 2 show that in this study majority of patients were primigravida constituting $53 \%$ and multigravida constituting $47 \%$. Considering chi-square test for this, value comes out to be 0.3 when $p=0.5$. Hence, the result is not statistically significant.

Table 2: Gravidity distribution.

\begin{tabular}{|lll|}
\hline Gravidity & Number & $\%$ (Present study) \\
\hline Primi & 58 & 53.0 \\
\hline Multi & 52 & 47.0 \\
\hline Total & 110 & 100 \\
\hline
\end{tabular}

Table 3: Conditions underlying bleeding per vaginum in $1^{\text {st }}$ trimester of pregnancy.

\begin{tabular}{|lll|}
\hline Condition & & Present study \\
\hline \multirow{2}{*}{ Abortions } & Threatened & $26(23.6 \%)$ \\
\cline { 2 - 3 } & Other & $22(20 \%)$ \\
\hline Ectopic pregnancy & $6(5.45 \%)$ \\
\hline H. Mole & $2(1.81 \%)$ \\
\hline Physiological & $54(49 \%)$ \\
\hline & $\mathrm{N}=110$ \\
\hline
\end{tabular}

Table 3 shows that in the present study, out of 110 patients, 48 patients presented with abortions, out of which 26 had threatened abortion and 22 had other abortions like incomplete abortion, blighted ovum, missed abortion, inevitable abortion, etc.

Table 4: Relation of history of previous pregnancy outcome in present pregnancy.

\begin{tabular}{|llll|}
\hline Outcome in & current pregnancy & Primigravida & Multigravidae \\
\cline { 2 - 4 } & Full term & 32 & 24 \\
\cline { 2 - 4 } Viable & Pre-term & 8 & 8 \\
\hline \multirow{5}{*}{ Nonviable } & Perinatal mortality/still birth & 5 & 1 \\
\cline { 2 - 4 } & Missed abortion & 0 & 6 \\
\cline { 2 - 4 } & Incomplete abortion & 2 & 2 \\
\cline { 2 - 4 } & Inevitable abortion & 0 & 3 \\
\cline { 2 - 4 } & Blighted ovum & 1 & 2 \\
\cline { 2 - 4 } & Ectopic pregnancy & 4 & 2 \\
\cline { 2 - 4 } & Vesicular mole & 4 & 2 \\
\cline { 2 - 4 } & Second trimester abortion/anencephaly & 1 & 2 \\
\hline
\end{tabular}

Out of 110, 2 patients had H. Mole and 6 had ectopic pregnancy. The rest 54 patients probably had physiological conditions underlying bleeding $\mathrm{PV}$ in $1^{\text {st }}$ trimester of pregnancy like implantation bleed and Hartman's sign.
Table 4 shows that in primi para with previous history of bleeding per vaginum had more chances to go in full term in present pregnancy in comparison to multigravida. Only one case of still birth noted in multipara. 
Table 5 shows that in 8-10 weeks pregnancy in USG scan there was $38 \%$ comes in bleeding per vaginum and $22 \%$ were in more than 10 weeks pregnancy.

Table 5: Gestational age according to USG at the time of bleeding.

\begin{tabular}{|llll|}
\hline $\begin{array}{l}\text { USG } \\
\text { finding }\end{array}$ & $\begin{array}{l}\text { Gestational } \\
\text { age in weeks }\end{array}$ & Number & $\begin{array}{l}\text { \% (Present } \\
\text { study) }\end{array}$ \\
\hline \multirow{3}{*}{ IUGS } & $4-6$ & 12 & 11 \\
\cline { 2 - 4 } & $6-8$ & 24 & 22 \\
\cline { 2 - 4 } & $8-10$ & 42 & 38 \\
\cline { 2 - 4 } & $>10$ & 24 & 22 \\
\hline Vesicular mole & 2 & 1.91 \\
\hline Ectopic & 6 & 5.09 \\
\hline Total & $\mathbf{1 1 0}$ & $\mathbf{1 0 0}$ \\
\hline
\end{tabular}

In this study, Table 6 shows that out of 110; subchorionic bleed was noted in 10 cases, 2 spontaneously aborted, 8 continued to term gestation of which, 5 were born full term health, 1 full term IUGR, 2 were preterm birth.

Hence favourable outcome was seen in 5 patients with $\mathrm{SCH}$ Hence, $50 \%$ of patients with $\mathrm{SCH}$ had favourable outcome and rest $50 \%$ had unfavourable outcome. Out of the rest 100 cases with no $\mathrm{SCH}$, favourable outcome was noted in 82 patients.

In this Table 7, all pregnancies with non-viable outcomes were excluded and only the ones with viable outcomes were studied further. Out of 77,48 patients $(62.3 \%)$ had vaginal delivery and $29(37.6 \%)$ had caesarean section and the commonest indication was foetal distress $(66 \%)$. The rate of caesarean section $(38 \%)$ is significantly high compared to that of the background population in which the rate of caesarean is $17.2 \%$.

\section{Table 6: Presence of sub chorionic hematoma $(\mathrm{SCH})$} and outcome.

\begin{tabular}{|lll|}
\hline \multirow{3}{*}{$\begin{array}{l}\text { SCH } \\
(\mathrm{N}=10)\end{array}$} & Favourable outcome & (Present study) $\%$ \\
\cline { 2 - 3 } & Spontaneous abortion & 20 \\
\cline { 2 - 3 } & IUGR & 10 \\
\cline { 2 - 3 } & Preterm & 10 \\
\hline $\begin{array}{l}\text { No SCH } \\
(\mathrm{N}=100)\end{array}$ & Favourable outcome & 82 \\
\hline
\end{tabular}

Table 7: Mode of delivery.

\begin{tabular}{|llll|}
\hline $\begin{array}{l}\text { Mode of } \\
\text { delivery }\end{array}$ & $\mathbf{N}=\mathbf{7 7}$ & $\begin{array}{l}\text { Present study } \\
(\%)\end{array}$ & $\begin{array}{l}\text { Total } \\
(\%)\end{array}$ \\
\hline FTND & 39 & 50.6 & \multirow{2}{*}{62} \\
\hline PTVD & 9 & 11.6 & \multirow{2}{*}{38} \\
\hline FTCS & 24 & 31.6 & \\
\hline PTCS & 5 & 6.4 & \\
\hline
\end{tabular}

\section{DISCUSSION}

In comparison with Williams et al, in which $86.5 \%$ patients were from 20-34 years. ${ }^{3}$ Also, $20 \%$ patients were of teenage pregnancy which is a significantly high rate compared to the background population in which $8 \%$ patients were of teenage pregnancy (NFHS-4, 20162018) where in our study the age group ranged from 1835 and majority (69\%) of first trimester bleeding occurs in age group of 21-30 years.

Study by Amirkhani Z et al, Karnatak, India 2013. ${ }^{4}$ Majority of cases were primigravida $56.7 \%$ and multigravida comprised of remaining $43.3 \%$. where in our study majority of patients were primigravida constituting $53 \%$ and multigravida constituting $47 \%$.

As in Figure 1 shows in Rani PR et al, 61\% were abortion and $21 \%$ ectopic pregnancy where in our study $43.6 \%$ abortion and in Sofat $\mathrm{R}$ et al, $70 \%$ were abortion. ${ }^{5,6}$

In present study, out of 110 patients with $1^{\text {st }}$ trimester bleeding per vaginum, 58 patients were primigravida in whom miscarriage rate was $56.7 \%$ (Amirkhani $\mathrm{Z}$ et al). ${ }^{4}$ Out of these 110,52 were multigravidae of which 34 patients had a history of previous viable outcome and 18 had a history of previous non-viable outcome. $24.5 \%$ cases of previous pregnancy spontaneous miscarriage were associated with present pregnancy abortion and $19 \%$ cases of previous pregnancy induced miscarriage were associated with present pregnancy abortion (Sipla P et al). ${ }^{7}$ Out of 52 multi-gravida, 44 had viable outcomes in current pregnancy while the rest 18 had nonviable outcomes. It suggests that history of abortion in previous pregnancy is a very strong predisposing factor for poor outcome in current pregnancy.

In this study majority $42(38 \%)$ of first trimester bleeding patients presented at 8-10 weeks which is comparable with Bharadvaj $\mathrm{N}$ et al, where $35 \%$ patient presented between 8-10 weeks. ${ }^{8}$ Hence the study shows congruence as per history and USG findings.

In this study Table 6 shows that out of 110; sub-chorionic bleed was noted in 10 cases, 2 spontaneously aborted, 8 continued to term gestation of which, 5 were born full term health, 1 full term IUGR, 2 were preterm birth, In Maso et al shows that favorable outcome was $61.5 \%$ in sub chorionic hematoma where in our study it was $50 \% .^{9}$

Table 8 shows that First trimester bleeding is also significantly associated with adverse maternal outcome observed in our 70 cases that extended beyond 20 weeks of pregnancy. Rest 40 did not extend beyond 20 weeks. out of the 70 , anemia $23(31 \%)$, placenta previa $2(2.8 \%)$, placenta abruption $6(8.5 \%)$, PPROM $14(20 \%)$ and PIH $6(8.5 \%)$. Hence, significant maternal morbidities are associated with patients who had bleeding per vaginum in their first trimester. thus, bleeding per vaginum can 
prognosticate the complications in the pregnancy (Table 8).

Table 9 shows first trimester bleeding is associated with increased rates of certain adverse fetal outcome. Observed in our cases: $16(20.7 \%)$ were preterm delivery, $6(8.6 \%)$ were IUGR. Perinatal death was $5(6.49 \%)$, out of which $4(80 \%)$ were still births due to abruptio placenta and rest $1(20 \%)$ was early neonatal death within 1 week of NICU admission due to preterm IUGR (Table 9).

\section{CONCLUSION}

There is a strong association between first trimester vaginal bleeding and adverse pregnancy outcome. The probability of abortion and adverse pregnancy outcome increases as the amount and duration of bleeding increases especially when accompanied with abdominal pain. The most common bleeding presentation in the study population was spotting per vaginum and most of these patients had a favourable outcome. Patients presenting with moderate amount of bleeding per vaginum were associated with strong underlying pathology and are not to be underestimated. Almost all the patients presenting with heavy bleeding per vaginum ended up in pregnancy loss and thus a poor outcome. In the presence of sub-chorionic hematoma, the prognosis of pregnancy is greatly affected as the risk of pre-term, IUGR and especially miscarriages increase significantly. In the women who experience first trimester vaginal bleeding, education and proper counselling of probable pregnancy outcomes can assist them to cope with their concerns and allay their anxiety. In view of high incidence of abortions and complications associated with first trimester bleeding there is a necessity of proper programming in care and also education of women belonging to the high-risk group. Identifying the risk factors associated with first trimester bleeding per vaginum; timely and appropriate management will be very helpful in reducing the complications like abortions, preterm birth, hypertensive disorders of pregnancy, antepartum and postpartum haemorrhage, etc. This will go a long way in reducing maternal and perinatal morbidity and mortality and overall pregnancy loss.

\section{Funding: No funding sources}

Conflict of interest: None declared

Ethical approval: The study was approved by the Institutional Ethics Committee

\section{REFERENCES}

1. Deutchman M, Tubay AT, Turok DK. First trimester bleeding. Am Fam Phys. 2009;79(11):985-92.
2. Evrenos AN, Gungor AN, Gulerman C, Cosar E. Obstetric outcomes of patients with abortus imminens in the first trimester. Arch Gynecol Obstet. 2014;289(3):499-504.

3. Williams MA, Mittendorf RO, Lieberman EL, Monson RR. Adverse infant outcomes associated with first-trimester vaginal bleeding. Obstet Gynecol. 1991;78(1):14-8.

4. Amirkhani Z, Akhlaghdoust M, Abedian M, Salehi GR, Zarbati N, Mogharehabed M, et al. Maternal and perinatal outcomes in pregnant women with first trimester vaginal bleeding. J Fam Reprod Health. 2013;7(2):57.

5. Reddirani P, Sunita V. Ultrasound evaluation of cause of vaginal bleeding in first trimester of pregnancy. J Obstet Gynecol Ind. 2000;50(1):54-8.

6. Sofat R. Ultrasound evaluation of bleeding in early pregnancy. J Obstet Gynecol Ind. 1987;31:344-7.

7. Sipila P, Haritikainen-Sorri AL, Oja H, Von Wendt L. Perinatal outcome of pregnancies complicated by vaginal bleeding. $\mathrm{Br} \mathrm{J}$ Obstet Gynecol. 1992;99(12):959-63.

8. Bharadwaj N. Sonography evaluation as an aid in the management of bleeding in early pregnancy. J Obstet Gynaecol India. 1998;38:640-2.

9. Maso G, D'Ottavio G, De Seta F, Sartore A, Piccoli M, Mandruzzato G. First-trimester intrauterine hematoma and outcome of pregnancy. Obstet Gynecol. 2005;105(2):339-44.

10. Davari TF, Shariat M, Kaveh M, Ebrahimi M, Jalalvand S. Threatened abortion: a risk factor for poor pregnancy outcome. Acta Medica Iranica. 2008;46(4):314-20.

11. Lykke JA, Dideriksen KL, Lidegaard $\varnothing$, LanghoffRoos J. First-trimester vaginal bleeding and complications later in pregnancy. Obstet Gynecol. 2010;115(5):935-44.

12. Kamble PD, Bava A, Shukla M, Nandanvar YS. First trimester bleeding and pregnancy outcome. Int $\mathbf{J}$ Reprod Contracept Obstet Gynecol. 2017;6:1484-7.

13. Sarmalkar MS, Singh S, Nayak AH, Das TK. Maternal and perinatal outcome in women with threatened abortion in first trimester. Int J Reprod Contracept Obstet Gynecol. 2016;5(5):1439.

Cite this article as: Bhatu JJ, Prajapati DS. A study of feto-maternal outcome in bleeding per vaginum in first trimester of pregnancy. Int J Reprod Contracept Obstet Gynecol 2020;9:1191-5. 